\title{
Estimation of Marine Boundary Layer Heights over the Western North Pacific Using GPS Radio Occultation Profiles
}

\author{
Fang-Ching Chien ${ }^{1}$, Jing-Shan Hong ${ }^{2}$, and Ying-Hwa Kuo ${ }^{3}$ \\ ${ }^{1}$ Department of Earth Sciences, National Taiwan Normal University, Taipei, Taiwan \\ ${ }^{2}$ Central Weather Bureau, Taipei, Taiwan \\ ${ }^{3}$ UCAR Community Programs, University Corporation for Atmospheric Research, Boulder, CO, USA
}

\begin{abstract}
This paper estimates marine boundary layer heights (MBLH) over the western North Pacific (WNP) using four years (20122015) of Global Positioning System radio occultation (GPSRO) profiles from the FORMOSAT-3/COSMIC satellites. Four methods of auto-detecting the MBLH are evaluated against observations from nearby island radiosonde stations. The two methods that use bending angle perform significantly better than the other two, which use refractivity profiles to estimate the MBLH. The MBLH is significantly higher in the winter than summer over the WNP, because winter exhibits a larger temperature difference between the WNP ocean surface and the lower atmosphere than does summer. Moreover, many regions with high MBLHs in winter are approximately located within the paths of the Kuroshio Current and the North Equatorial Current. When these warm ocean currents flow under relatively colder air, favorable conditions for convection develop, resulting in a higher MBLH.
\end{abstract}

(Citation: Chien, F.-C., J.-S. Hong, and Y.-H. Kuo, 2016: Estimation of marine boundary layer heights over the western North Pacific using GPS radio occultation profiles. SOLA, 12, 302-306, doi:10.2151/sola.2016-059.)

\section{Introduction}

The marine boundary layer height (MBLH) is an important parameter in determining radiation effects on the Earth's radiation budget in climate models, particularly because it usually represents a marine boundary layer (MBL) stratocumulus cloud top (Norris 1998; Wood 2012). Unfortunately, it is more difficult to accurately estimate the MBLH than the planetary boundary layer (PBL) height over land, owing to the fact that in situ observations over ocean are scarce. Since the April 2006 launch of the Formosa Satellite Mission 3 (FORMOSAT-3)/Constellation Observing System for Meteorology, Ionosphere, and Climate (COSMIC), many studies have demonstrated that Global Positioning System radio occultation (GPS-RO) data with high resolution in the lower atmosphere are useful in detecting the MBLH (e.g., Sokolovskiy et al. 2006, 2007; Basha and Ratnam 2009; Guo et al. 2011; Ao et al. 2012; Xie et al. 2012; Ho et al. 2014). There are three principle reasons for this: first, the GPS signal in the L-band microwave frequencies can pass through clouds and precipitation basically unaffected; second, the limb-viewing GPS-RO profile has a fairly high vertical resolution $(\sim 100 \mathrm{~m})$, such that it can effectively detect the fine structure near the PBL top; and third, GPS-RO data have excellent global coverage (Kursinski et al. 1997).

Since the transition from the PBL to the free atmosphere is usually characterized by a significant change in temperature and water vapor, the PBL height (or MBLH) can be easily defined at an altitude where the greatest decrease occurs in the vertical profile of bending angle, refractivity, or water vapor pressure. A simple approach, therefore, is to define the top of the PBL at the

Corresponding author: Fang-Ching Chien, Department of Earth Sciences, National Taiwan Normal University, No. 88, Section 4, Ting-Chou Road, Taipei, 11677, Taiwan. E-mail: jfj@ntnu.edu.tw. (C2016, the Meteorological Society of Japan. altitude of the minimum vertical gradient of any of these three parameters (Sokolovskiy et al. 2006; Basha and Ratnam 2009; Ao et al. 2012; Xie et al. 2012; Ho et al. 2014). A similar but slightly different approach is to identify the PBL height as the altitude where the lapse rate of refractivity changes the most (the so-called breakpoint) (Sokolovskiy et al. 2006; Guo et al. 2011; Ho et al. 2014). Another method is illustrated by Sokolovskiy et al. (2007), which defined the PBL height by searching for the altitude using a maximum of $P$,

$$
P \equiv \Delta \alpha\left(\frac{\Delta \alpha}{\Delta z}\right)
$$

where $\Delta \alpha$ is the bending angle lapse, and $\Delta \alpha / \Delta z$ is the vertical gradient of bending angle. This method is a trade-off between the maximal lapse and the maximal gradient of bending angle.

Although the aforementioned methods have been previously proposed to estimate the MBLH, there has been no thorough evaluation and comparison among them up until now. It thus remains unknown which method and parameter being used give the best estimate. In addition, a review of the literature revealed relatively few studies that investigate the MBLH over the western North Pacific (WNP). Accordingly, it has been difficult to evaluate the performance of numerical weather prediction products over the WNP with respect to phenomena relating to oceanic boundary layer processes. Using the GPS-RO data from the FORMOSAT-3/ COSMIC satellites from 2012 to 2015 , this paper aims to evaluate the methods of determining MBLH, to estimate the WNP MBLH, and to study seasonal and regional variations of the MBLH.

\section{Methods}

This paper compares four methods of estimating MBLH, using GPS-RO data from the FORMOSAT-3/COSMIC satellites in 2012-2015. The first one (MXP-BA), adopted from Sokolovskiy et al. (2007), uses bending angle to define the MBLH. The second method (MG-BA) defines the MBLH as the altitude of the minimum gradient of bending angle. The third method (BP-Ref) estimates the MBLH by finding the break point in a refractivity profile. The final method (MG-Ref) is similar to the MG-BA, but uses refractivity instead of bending angle. Because RO profiles often contain sharp vertical structures between layers as a result of local perturbations, which need to be removed before any estimation procedure, the bending angle and refractivity profiles are first smoothed by a $250 \mathrm{~m}$ window.

The GPS-RO profiles that are collocated with fifteen island radiosonde stations over the WNP (Fig. 1) within $250 \mathrm{~km}$ horizontal distance and $3 \mathrm{~h}$ time window are used to determine the MBLH following the aforementioned methods. The MBLHs are then compared with those defined subjectively from the collocated sounding observations. In total, there are 1411 of such cases available over the WNP in 2012-2015. Their traces that pass through the lower atmosphere $(\leq 5 \mathrm{~km})$ are shown in Fig. 1. Among the 15 stations, five stations provide observations with higher mean vertical resolution ranging from $160-190 \mathrm{~m}$ in the lower troposphere, and the others varying from 300-390 m. Because not all the cases had a clear MBLH, we examined their temperature and water vapor pressure profiles and identified their MBLHs with a 


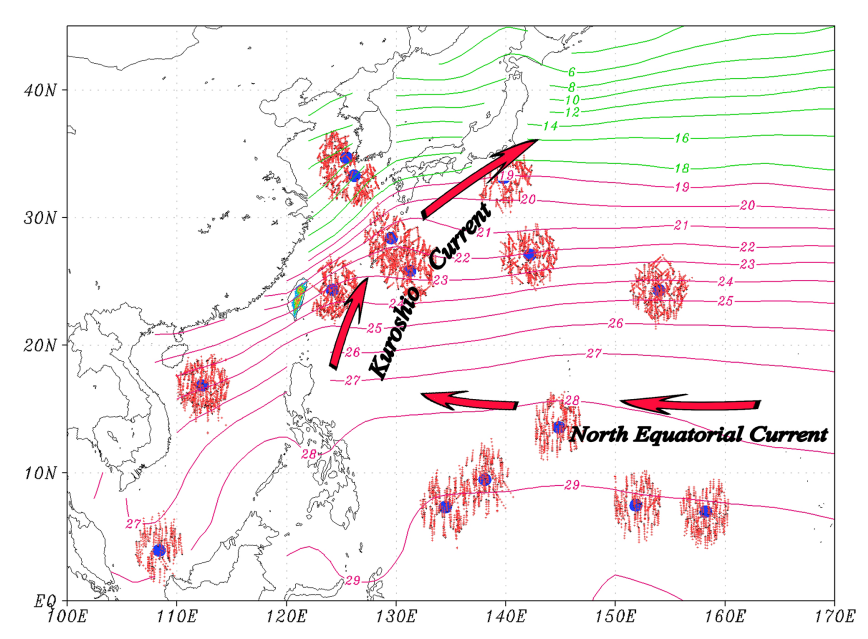

Fig. 1. Locations of the 15 island sounding stations (blue dots) over the western North Pacific Ocean. Tiny red crosses show $0-5-\mathrm{km}$ traces of the nearby GPS-RO profiles that are used for evaluation, with a black cross indicating the location at $5 \mathrm{~km}$. The winter SST averaged in December, January, and February, $2012-2015$ is plotted in green lines $\left(2^{\circ} \mathrm{C}\right.$ interval) and purple lines $\left(1^{\circ} \mathrm{C}\right.$ interval $)$, using the NOAA Extended Reconstructed Sea Surface Temperature (ERSST) data. The Kuroshio Current and the North Equatorial Current are also denoted.

confidence parameter (CP) of 1 to 3 . When a sounding exhibited a clear temperature inversion and a sharp-decreasing moisture profile, it was assigned by a $\mathrm{CP}$ of 3 . If either of the above two conditions did not meet, a CP of 2 was given. For the remaining cases in which either the GPS RO did not reach the altitude of the MBLH identified by soundings or there were problems with the profiles, the $\mathrm{CP}$ was 1 . Overall, 216 cases were found to have a clear MBLH with a CP of 3. An example of such cases occurred at an island station (Minamitorishima) at 0000 UTC 17 March 2012 (Fig. 2). The MBLH was identified at about $2.2 \mathrm{~km}$ where a temperature inversion and a sharp decrease in water vapor pressure occurred (Fig. 2a). The GPS-RO bending angle profile taken at 2125 UTC 16 March 2012 and at a location $\sim 40 \mathrm{~km}$ away exhibited a sharp drop at nearly the same height $(\sim 2 \mathrm{~km})$ where the min-
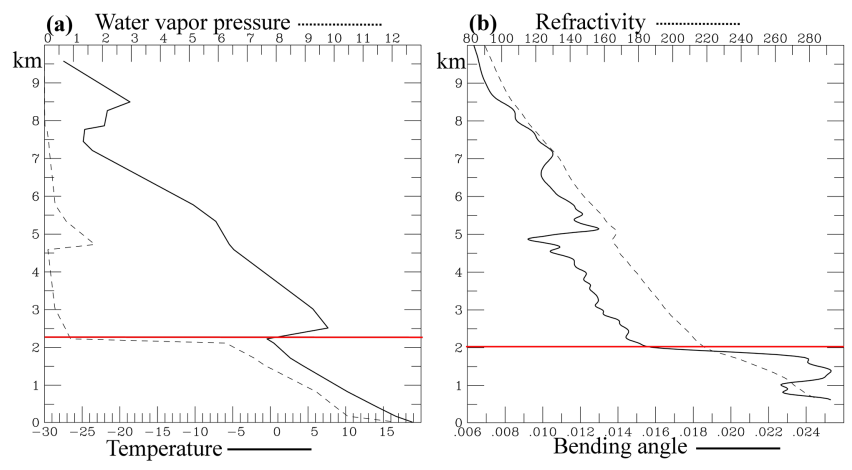

Fig. 2. An example of a sounding observation that has a clear MBL height with a $\mathrm{CP}$ of 3 . The island station is located at Minamitorishima $\left(24.3^{\circ} \mathrm{N}\right.$, $\left.154^{\circ} \mathrm{E}\right)$. (a) Temperature $\left({ }^{\circ} \mathrm{C}\right.$, scale on the bottom) and water vapor pressure (hPa, scale on the top) taken at 0000 UTC 17 March 2012 are plotted in solid and dashed lines, respectively. (b) Bending angle (scale on the bottom) and refractivity (scale on the top) of the collocated GPS-RO profile taken at 2125 UTC 16 March 2012 are plotted in solid and dashed lines, respectively. The estimated MBLH is indicated by a red line. Height is from 0 to $10 \mathrm{~km}$.

imum refractivity gradient also occurred (Fig. 2b). The difference of MBLH between the GPS-RO and the sounding observations for this case was about $200 \mathrm{~m}$.

\section{Evaluation results}

In order to fairly evaluate the performance of each method, we only choose cases with a clear MBLH $(\mathrm{CP}=3)$. Figure 3 presents scattered diagrams with linear regression of the MBLHs estimated from the four methods against those determined from the radiosonde observations. The corresponding slope and $\mathrm{R}$ square (hereafter, R2) are also summarized in Table 1. It is clear that the MBLHs estimated by the MXP-BA, with the best slope $(\sim 0.99)$ and the highest R2 ( 0.7), have the best fit with those from the sounding observations among the four methods (Fig. 3a). The MG-BA (Fig. 3b) also reliably estimates the MBLH, but its R2
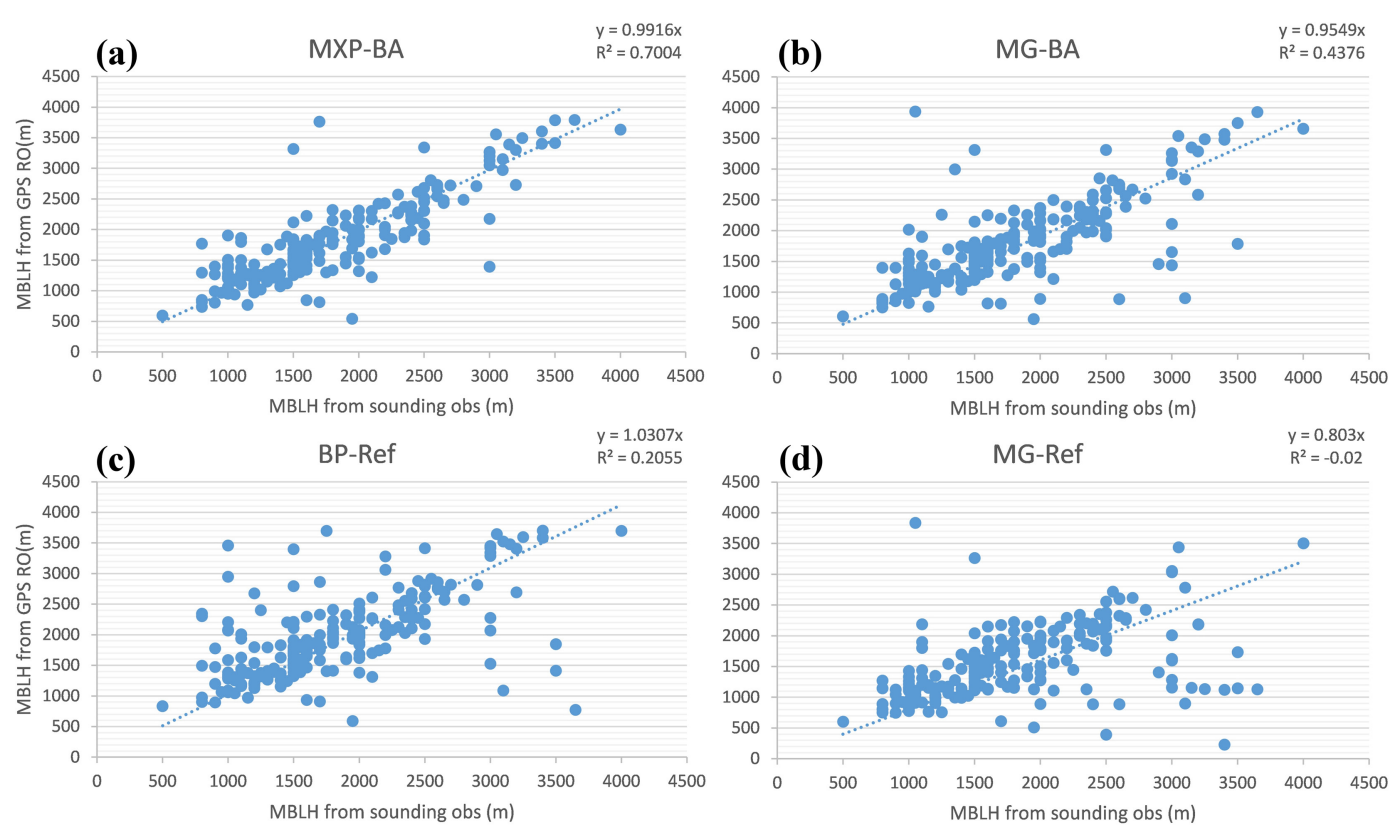

Fig. 3. Scattered diagrams of the MBLH estimated from island radiosonde stations (the abscissa) and from GPS-RO profiles (the ordinate) using the four methods: (a) MXP-BA, (b) MG-BA, (c) BP-Ref, and (d) MG-Ref. The cases are filtered by a confidence parameter (CP) of 3. The best fit of linear regression with an intercept of zero is denoted, along with the slope and the $\mathrm{R}$ square. 
Table 1. The mean marine boundary layer height (MBLH, meter) estimated by the four methods (MXP-BA, MG-BA, BP-Ref, and MG-Ref). The cases from 2012 to 2015 were filtered for those with a CP of 3 in the sounding observations before taking the average (ALL). The average is also sub-grouped into four seasons (DJF, MAM, JJA, and SON). The slope and R square of the linear regression of the MBLH between the GPS-RO and island sounding observations with an intercept of zero for ALL are also denoted.

\begin{tabular}{lccccc}
\hline \multicolumn{1}{c}{ CP(3) } & & MXP-BA & MG-BA & BP-Ref & MG-Ref \\
\hline DJF (winter) & MBLH & 1926.2 & 1899.6 & 2014.3 & 1607.4 \\
\hline MAM (spring) & MBLH & 1648.8 & 1684.8 & 1831.8 & 1471.6 \\
\hline JJA (summer) & MBLH & 1779.4 & 1732.5 & 2129.4 & 1361.1 \\
\hline \multirow{2}{*}{ SON (fall) } & MBLH & 1987.0 & 1792.0 & 2061.7 & 1710.0 \\
\hline \multirow{3}{*}{ ALL (4-year) } & MBLH & 1836.7 & 1794.3 & 1977.5 & 1561.2 \\
& Slope & 0.99 & 0.95 & 1.03 & 0.80 \\
& $\mathrm{R}^{2}$ & 0.70 & 0.44 & 0.21 & -0.02 \\
\hline
\end{tabular}

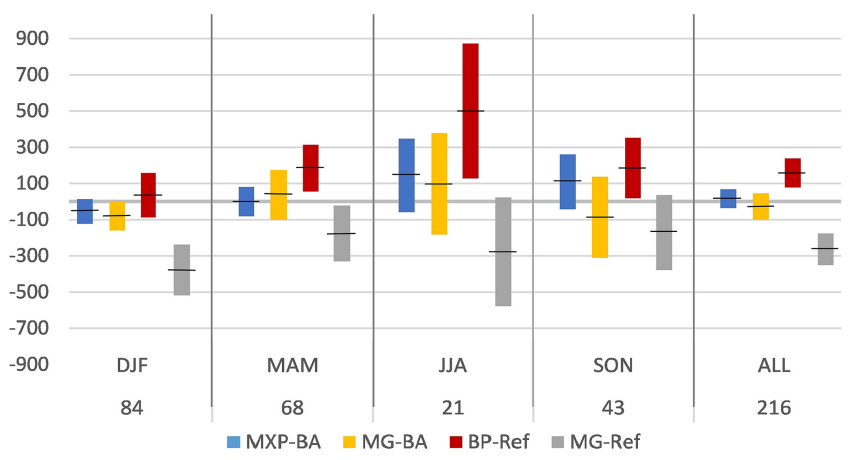

Fig. 4. Mean errors (line segment) and the $95 \%$ confidence interval of the mean error (color bar) of the MBLH estimated from GPS-RO profiles by the four methods, using the MBLH defined from the island sounding stations as the truth. The cases are filtered by a confidence parameter (CP) of 3. Numbers in the bottom denote data amounts. Besides the average for 4 years (ALL), seasonal averages are also shown (DJF: winter, MAM: spring, JJA: summer, and SON: autumn).

( 0.44) is lower than that of the MXP-BA. The BP-Ref (Fig. 3c) overestimates the MBLH with a low R2 $(\sim 0.2)$, while the MG-Ref (Fig. 3d) underestimates the MBLH with an even lower R2.

Figure 4 presents the mean error (the line segment) of the MBLHs estimated from the four methods against the sounding observations for the cases with a $\mathrm{CP}$ of 3 . In addition, the standard error of the mean error, which is defined as the ratio of standard deviation of the mean error to the square root of the sample size (data amount), is multiplied by its associated Student's $t$ value to determine the $95 \%$ confidence interval of the mean error (denoted as color bars above and below the mean in Fig. 4). Besides presenting the average of the four years of data (ALL), we also grouped the data into four different seasons (DJF: winter, MAM: spring, JJA: summer, and SON: fall). The corresponding mean MBLHs are further summarized in Table 1. Summer has the least amount of data such that it shows the largest variation in the mean error and the $95 \%$ confidence interval among the four seasons. The MXP-BA slightly underestimates the MBLH in winter (DJF), but it overestimates the MBLH in all other seasons. As a result, its overall mean errors (ALL) reveal a higher mean MBLH than the sounding observations. The MG-BA underestimates the MBLH in both winter and autumn. Although it overestimates the spring and summer data, this method still slightly underestimates the MBLH in ALL. Overall the mean error of the MXP-BA $(14.7 \mathrm{~m})$ is closer to zero than that of the MG-BA $(-27.7 \mathrm{~m})$, but the difference of their mean errors does not reach the $95 \%$ confidence level. The two methods that use refractivity (BP-Ref and MG-Ref) have larger mean errors, with the former overestimating and the latter underestimating the MBLH. They are significantly (exceeding the $95 \%$ confidence level) worse than the other two that use bending angle to estimate the MBLH.

\section{The MBLH over the WNP}

The previous section suggests that the MXP-BA, among the four chosen methods, provides the best estimate of MBLH at locations where nearby radiosonde stations indicate a clear MBLH. However, in order to estimate the MBLH over the entire WNP, an auto-detecting method is needed. In this situation, is the MXP-BA still the best? To answer this question, we use a sharpness parameter (SP) suggested by Ao et al. (2012) to identify the quality of the MBLH estimated from the GPS-RO data. For the two MG methods (MG-BA and MG-Ref), SP is defined as follows,

$$
S P \equiv-\frac{X_{\min }^{\prime}}{X_{R M S}^{\prime}},
$$

where $X^{\prime}$ is the vertical gradient of either bending angle or refractivity, $X_{\min }^{\prime}$ is the minimum of $X^{\prime}$, and $X_{\mathrm{RMS}}^{\prime}$ is the root-mean square (RMS) of $X^{\prime}$ over the altitude range under consideration (0-4 $\mathrm{km})$. Basically, an SP quantifies how large a minimum gradient is, where the MBLH is defined, relative to the average gradient. The larger the SP associated with an estimated MBLH, the more dominant the minimum gradient and thus the more trustworthy the estimate. For the MXP-BA, it is difficult to compute such a parameter. We therefore use the SP from the MG-BA to represent its sharpness, since they use the same data source: bending angle. For the BP-Ref, a similar approach is applied, with $X^{\prime}$ being the lapse of the slopes of the refractivity profile within a vertical range. SP is now defined as the ratio of the maximum $X^{\prime}$ (where the break point and MBLH are located) to the RMS of $X^{\prime}$ over the altitude range under consideration $(0-4 \mathrm{~km})$.

In Section 3, we identified 216 cases (out of 1411) with a well-defined MBLH based off temperature and moisture profiles from the island soundings. This percentage $(\sim 15 \%)$ is used in determining an SP threshold for each method, which is 3.2, 3.2, 2.7, and 2.1 for the MXP-BA, MG-BA, BP-Ref, and MG-Ref, respectively. When an assessed MBLH has an SP larger than this threshold, it is assumed to be of good quality and is collected for verification. Figure 5 presents the mean error of the MBLHs from the four methods against the sounding observations for the cases filtered by these SP thresholds. Data amounts are slightly different owing to diverse SP thresholds among methods. The corresponding mean MBLHs are also summarized in Table 2. For the most part, the $95 \%$ confidence intervals of the mean error in Fig. 5 are larger than those in Fig. 4. In addition, the data points in the corresponding scattered diagrams (figure not shown, but the associated slope and R2 are summarized in Table 2) are more scattered than those in Fig. 3, and the R2s in Table 2 are all smaller than those in Table 1. The various case selecting processes cause this variation. The evaluated cases in Fig. 4 are picked up subjectively, as $\mathrm{CP}$ is identified manually, while those in Fig. 5 are filtered objectively. When a case has a high CP, it is quite certain that a clear MBLH exists and is very likely that the associated GPS-RO profile will accurately indicate the MBLH. However, a high SP may not guarantee a clear MBLH in the GPS-RO profile, because the auto-detecting methods do not always perfectly determine the MBLH. For such cases, their associated CPs may not be 3. Ideally, these two sets of data would have a large intersection; however, the multiple sources of errors in our estimation diminish this possibility. These sources may include the error from the GPS bending angle and refractivity, the error owing to the space and time differences between the sounding and GPS-RO profiles, and the error from our methods.

A further comparison between Figs. 4 and 5 demonstrates that the relative performance between the four methods for the cases filtered by SP is, in general, similar to that for the cases selected using CP. For the mean of the 4-year data (ALL), the MXP-BA 


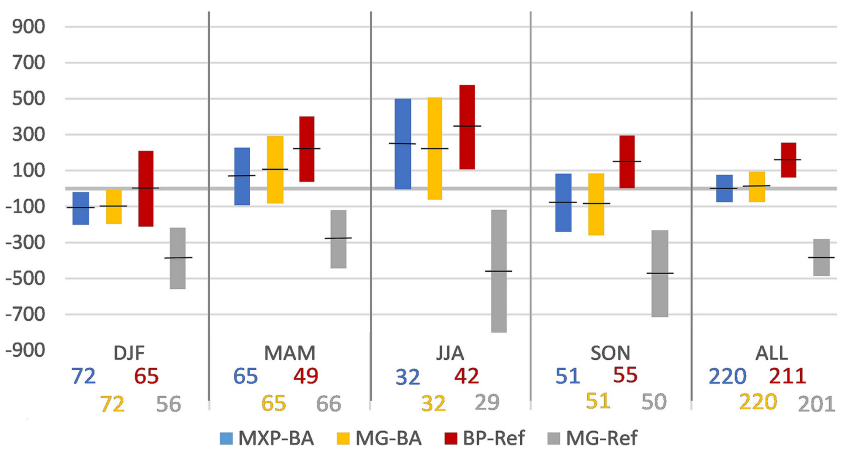

Fig. 5. Same as Fig. 4, but for the cases filtered by their sharpness parameter (SP).

delivers MBLHs with the smallest mean errors. The MG-BA is the second best in performance. The difference between the two methods is small and does not reach the $95 \%$ confidence level, but they are both significantly better than the other two. In particular, the MXP-BA out-performs the BP-Ref and MG-Ref with a confidence level exceeding 95\%. Finally, the BP-Ref overestimates and the MG-Ref underestimates the MBLH.

We can now have a higher degree of confidence in using the
Table 2. Same as in Table 1, but for cases filtered by sharpness parameter (SP). The SP thresholds for the MXP-BA, MG-BA, BP-Ref, and MG-Ref are $3.2,3.2,2.7$, and 2.1 , respectively.

\begin{tabular}{lccccc}
\hline \multicolumn{1}{c}{ SP } & & MXP-BA & MG-BA & BP-Ref & MG-Ref \\
\hline DJF (winter) & MBLH & 1730.3 & 1740.9 & 1929.9 & 1369.9 \\
\hline MAM (spring) & MBLH & 1465.6 & 1503.2 & 1812.3 & 1119.3 \\
\hline JJA (summer) & MBLH & 1752.1 & 1723.9 & 1995.5 & 1192.2 \\
\hline \multirow{2}{*}{ SON (fall) } & MBLH & 1508.1 & 1500.0 & 1901.6 & 1280.8 \\
\hline \multirow{3}{*}{ ALL (4-year) } & MBLH & 1603.8 & 1612.4 & 1908.3 & 1239.8 \\
& Slope & 0.95 & 0.96 & 1.01 & 0.68 \\
& $\mathrm{R}^{2}$ & 0.34 & 0.29 & 0.17 & -0.46 \\
\hline
\end{tabular}

MXP-BA to automatically detect the MBLH over the entire WNP. From all the GPS-RO data available in 2012-2015, 7858 profiles that are located in the domain of $100^{\circ} \mathrm{E}-170^{\circ} \mathrm{E}$ and $0^{\circ} \mathrm{N}-45^{\circ} \mathrm{N}$ (Fig. 1) have a SP greater than 3.2. In order to display regional distribution of MBLH over this particular area, we group the data into $5^{\circ} \times 5^{\circ}$ boxes and compute the average MBLH for each box (Fig. 6). In addition to presenting the 4-year average result, we also categorize the data into the four seasons. A cubic interpola-
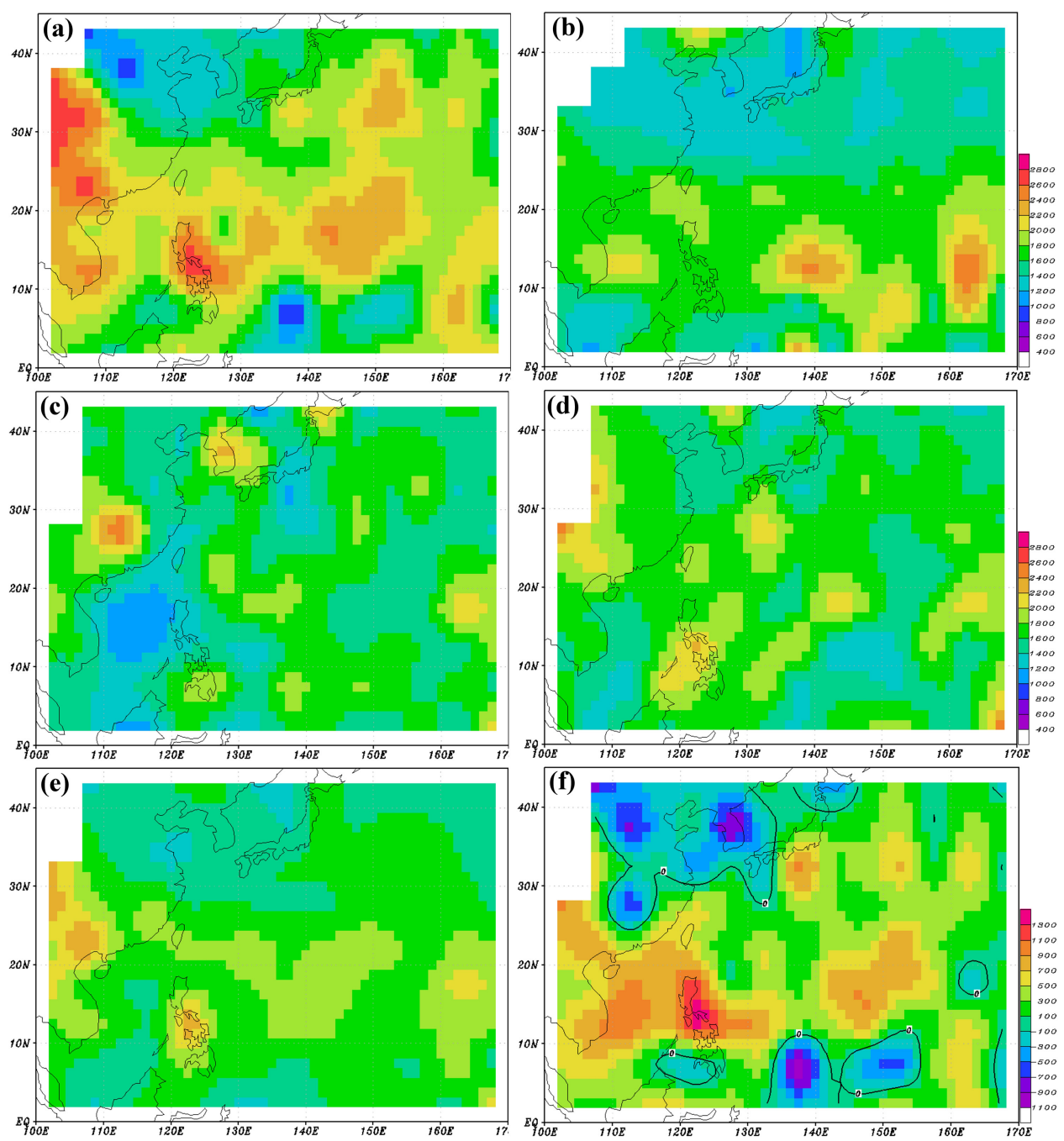

Fig. 6. (a-d) The seasonally-averaged MBLH for winter, spring, summer, and autumn, respectively, and (e) the 4-year average MBLH using GPS-RO profiles from 2012 to 2015 . The difference between (a) winter and (c) summer is also shown in (f). Note that the color index for (f) is different to that of (a-e) which is shown in the right of (b) and (d). 
tion is applied before plotting.

Figure 6 shows that the MBLH is significantly higher in the winter than summer over the WNP. This is due to the temperature difference between the ocean surface and the lower atmosphere, which is larger in the winter than summer over the WNP. In winter, the MBLHs are higher than $2000 \mathrm{~m}$ over large areas of the WNP, including the northern South China Sea, oceans near Taiwan and southward to the Philippines, and regions farther to the east at $140^{\circ} \mathrm{E}-155^{\circ} \mathrm{E}$ (Fig. 6a). Note that the larger MBLHs are more concentrated around the latitudes between $10^{\circ} \mathrm{N}$ and $25^{\circ} \mathrm{N}$. Compared with the distribution of ocean currents (Qiu 2001) and mean sea surface temperature over the WNP (Fig. 1), these relatively high MBLH regions are approximately located within the paths of the Kuroshio Current and the North Equatorial Current. These warm ocean currents flow under relatively colder air in the winter, developing favorable conditions for convection and a higher MBLH. The average MBLH is relatively lower over the Yellow Sea because a cold ocean current is present there in the winter. In the summer, the average MBLHs over the WNP are mostly lower than $2000 \mathrm{~m}$, except for a small region near $17^{\circ} \mathrm{N}, 165^{\circ} \mathrm{E}$ (Fig. 6c). The temperature difference between the ocean surface and the atmosphere is much smaller in the summer than winter over the WNP. As a result, the MBLH in the summer is generally lower. The mean MBLHs in the spring and autumn (Figs. 6b, d) fall between those of the winter and summer. Figure $6 f$ further presents the difference of MBLH between winter and summer. This seasonal variation of MBLH over the WNP is consistent with Ao et al. (2012), although they used the MG-Ref, instead of the MXP-BA, and the different years of the GPS-RO profiles.

For the 4-year average, the MBLHs over the WNP range from $\sim 1400$ to $2200 \mathrm{~m}$ (Fig. 6e). Larger values $(1800-2000 \mathrm{~m})$ are present near the subtropical area extending from southern Taiwan eastward to the central Pacific. Oceans east of the Philippines, Taiwan, and Japan are also covered with relatively large MBLH values (1600-1800 m). Similar to those described above, these higher MBLHs relate to the unstable conditions created when warm ocean currents flow below and relatively colder air flows above, which is especially prolific during cold seasons.

\section{Summary}

This paper presents an evaluation of methods that estimate the MBLH over the WNP using GPS-RO profiles from the FORMOSAT-3/COSMIC satellites from 2012-2015. Four methods of auto-detecting the MBLH were chosen, including the MXP-BA, MG-BA, BP-Ref, and MG-Ref. The first two methods utilize bending angle and the second two use refractivity to determine the MBLH. The performance of each method is first evaluated by comparing the estimated MBLHs with those defined manually from nearby island sounding stations. The results show that the two methods that use bending angle perform significantly better than the other two that use refractivity to estimate the MBLH. The MXP-BA is slightly better than the MG-BA. The BP-Ref overestimates the MBLH, while the MG-Ref underestimates the MBLH when compared with the MBLH from the sounding observations.

Using an SP to determine the quality of an auto-detected MBLH can effectively select for cases with a clearer MBLH. When cases are filtered using their SPs, the MXP-BA had the best estimate of MBLH among the four methods. It is therefore applied to compute the average MBLH over the entire WNP. The results show that the MBLH is significantly higher in the winter than summer over the WNP. This is because the temperature difference between the ocean surface and the lower atmosphere is larger in the winter than summer over the WNP. The high MBLHs are approximately located within the paths of the Kuroshio Current and the North Equatorial Current. These higher MBLHs relate to the unstable conditions created when warm ocean currents flow below, and relatively colder air flows above, which is especially prolific during cold seasons.

\section{Acknowledgements}

The data used in this study are obtained from the TACC (Taiwan Analysis Center for COSMIC) website (http://tacc.cwb. gov.tw/). This research was supported by the National Space Organization (Grant NSPO-S-104042 and Grant NSPO-S-105110) and Ministry of Science and Technology of Taiwan (Grant MOST 104-2111-M-003-003). We thank Dr. S. V. Sokolovskiy for providing the source code applied in the MXP-BA method and Dr. ShuPeng Ho and Dr. Chi O. Ao for offering constructive suggestions during the paper preparation.

Edited by: H. Hashiguchi

\section{References}

Ao, C. O., D. E. Waliser, S. K. Chan, J.-L. Li, B. Tian, F. Xie, and A. J. Mannucci, 2012: Planetary boundary layer heights from GPS radio occultation refractivity and humidity profiles. $J$. Geophys. Res., 117, D16117, doi:10.1029/2012JD017598.

Basha, G., and M. V. Ratnam, 2009: Identification of atmospheric boundary layer height over a tropical station using highresolution radiosonde refractivity profiles: Comparison with GPS radio occultation measurements. J. Geophys. Res., 114, D16101, doi:10.1029/2008JD011692.

Guo, P., Y.-H. Kuo, S. V. Sokolovskiy, and D. H. Lenschow, 2011: Estimating atmospheric boundary layer depth using COSMIC radio occultation data. J. Atmos. Sci., 68, 17031713, doi:10.1175/2011JAS3612.1.

Ho, S.-P., L. Peng, R. A. Anthes, Y.-H. Kuo, and H.-C. Lin, 2014: Marine boundary layer heights and their longitudinal, diurnal, and interseasonal variability in the Southeastern Pacific using COSMIC, CALIOP, and radiosonde data. J. Climate, 28, 2856-2872.

Kursinski, E. R., G. A. Hajj, J. T. Schofield, R. P. Linfield, and K. R. Hardy, 1997: Observing Earth's atmosphere with radio occultation measurements using the Global Positioning System. J. Geophys. Res., 102(D19), 23429-23465, doi: 10.1029/97JD01569.

Norris, J. R., 1998: Low cloud type over the ocean from surface observations. Part I: Relationship to surface meteorology and the vertical distribution of temperature and moisture. $\mathrm{J}$. Climate, 11, 369-382, doi:10.1175/1520-0442(1998)011,0369: LCTOTO.2.0.CO;2.

Qiu, B., 2001: Kuroshio and Oyashio currents. Encyclopedia of Ocean Sciences, Academic Press, pp.1413-1425.

Sokolovskiy, S. V., Y.-H. Kuo, C. Rocken, W. S. Schreiner, D. Hunt, and R. A. Anthes, 2006: Monitoring the atmospheric boundary layer by GPS radio occultation signals recorded in the open-loop mode. Geophys. Res. Lett., 33, L12813, doi: 10.1029/2006GL025955.

Sokolovskiy, S. V., C. Rocken, D. H. Lenschow, Y.-H. Kuo, R. A. Anthes, W. S. Schreiner, and D. C. Hunt, 2007: Observing the moist troposphere with radio occultation signals from COSMIC. Geophys. Res. Lett., 34, L18802, doi:10.1029/ 2007GL030458.

Wood, R., 2012: Stratocumulus clouds. Mon. Wea. Rev., 140, 2373-2423, doi:10.1175/MWR-D-11-00121.1.

Xie, F., D. L. Wu, C. O. Ao, A. J. Mannucci, and E. R. Kursinski, 2012: Advances and limitations of atmospheric boundary layer observations with GPS occultation over southeast Pacific Ocean. Atmos. Chem. Phys., 12, 903-918, doi: 10.5194/acp-12-903-2012.

Manuscript received 1 August 2016, accepted 15 October 2016

SOLA: https://www.jstage.jst.go.jp/browse/solal 